\title{
Differential expression of cyclin-dependent kinase inhibitors, p27Kip1 and p57Kip2, by corticotropin in rat adrenal cortex
}

\author{
Hironobu Kobayashi ${ }^{1,2}$, Fukushi Kambe ${ }^{1}$, Tsuneo Imai ${ }^{2}$, \\ Yatsuka Hibi ${ }^{2}$, Toyone Kikumori ${ }^{2}$, Sachiko Ohmori ${ }^{1}$, \\ Akimasa $\mathrm{Nakao}^{3}$ and Hisao Seo ${ }^{1}$ \\ ${ }^{1}$ Department of Endocrinology and Metabolism, Division of Molecular and Cellular Adaptation, Research Institute of Environmental Medicine, \\ Nagoya University, Furo-cho, Chikusa-ku, Nagoya, 464-8601, Japan \\ ${ }^{2}$ Department of Breast and Endocrine Surgery, Nagoya University School of Medicine, Tsurumai-cho, Showa-ku, Nagoya, 466-8550, Japan \\ ${ }^{3}$ Second Department of Surgery, Nagoya University School of Medicine, Tsurumai-cho, Showa-ku, Nagoya, 466-8550, Japan \\ (Requests for offprints should be addressed to F Kambe; Email: kambe@riem.nagoya-u.ac.jp)
}

\begin{abstract}
An important role for the cyclin-dependent kinase inhibitors (CDKIs), p27Kip1 and p57Kip2, in the proliferation and differentiation of adrenal cells has been suggested by their knockout mice, which display adrenal hyperplasia. Adrenal development and function are primarily regulated by ACTH. In the present study, we investigated the effects of ACTH on the expression of p27Kip1, p57Kip2 and proliferating cell nuclear antigen (PCNA) in rat adrenals. Male Wistar rats were treated with dexamethasone (Dex) to inhibit endogenous ACTH secretion. ACTH was then administered to the rats, and the adrenals were examined by Western blot and immunohistochemical analyses. Dex treatment induced shrinkage of adrenals where no PCNA-expressing cells were detected, but most of the cells expressed p27Kip1. Subsequent $\mathrm{ACTH}$ treatment resulted in the marked suppression of
\end{abstract}

p27Kip1 expression, specifically in adrenocortical cells at $12 \mathrm{~h}$ after the stimulus. At $48 \mathrm{~h}$, the p27Kip 1 suppression still continued in the cortex, while the PCNA-expressing cells appeared mainly around the zona glomerulosa and increased at $72 \mathrm{~h}$. At this time, the p27Kip1-expressing cells also appeared in the same zone. In contrast to p27Kip1, the expression of p57Kip2 was not detected in the Dex-treated adrenal. However, its expression was markedly induced by ACTH in the zona glomerulosa at 48 and $72 \mathrm{~h}$. The results demonstrate that the primary site for mitogenic action of ACTH in rat adrenocortex is the zona glomerulosa, and that ACTH modulates proliferation of adrenocortical cells by regulating p27Kip1 and p57Kip2 expression in a time- and site-specific manner. Journal of Endocrinology (2006) 189, 671-679

\section{Introduction}

Adrenocorticotropic hormone (ACTH, corticotropin), one of the pituitary hormones, is the primary regulator for fetal adrenal development and adult adrenal functions. ACTH exerts its effects mainly through a guanine nucleotide-binding protein ( $G$ protein)-coupled receptor, ACTH receptor (ACTHR), present in the plasma membrane of adrenocortical cells. The adrenal is composed of two distinct tissues, cortex and medulla, and the former consists of three major zones of cells arranged as concentric shells: the zona glomerulosa, the zona fasciculata and the zona reticularis. In all three zones of the cortex, ACTHR expression has been demonstrated in humans and rodents, although the expression level in each zone appears to vary among species (Xia \& Wikberg 1996, Reincke et al. 1998, Muller et al. 2001). ACTH stimulates the synthesis and secretion of glucocorticoids, mineralocorticoids and adrenal androgen via ACTHR
(Rosenfeld et al. 1975, Kater et al. 1989); it also induces the proliferation of adrenocortical cells (Wright et al. 1974, Imai et al. 1990). In clinical and animal studies, it has been established that circulating ACTH levels are positively correlated with the size of the adrenals, and that chronic hypersecretion of ACTH induces bilateral diffuse hyperplasia of adrenals (Bland et al. 2003). ACTH has been thus considered as a mitogenic hormone for adrenals. However, in in vitro situations, it was reported that ACTH has inhibitory as well as stimulatory actions on the proliferation of adrenocortical cells (Hornsby \& Gill 1977, Arola et al. 1993, Lotfi et al. 1997).

Modulation of cell proliferation and differentiation is closely associated with the regulation of cell cycle progression. Signals that drive cells into mitosis converge on the regulation of cyclin-dependent kinases (CDKs). The activities of CDKs are regulated by multiple mechanisms, which include the intracellular levels of cyclin accumulation and assembly of cyclin-CDK complexes, phosphorylation status 
of the kinases and the presence of CDK inhibitors (CDKIs) (Sherr \& Roberts 1999, Vidal \& Koff 2000). CDKIs suppress CDK activities by physical association or by blocking substrate/ATP access. To date, they are classified into two families according to structural similarities. The Ink 4 family is made up of four proteins that share a common structural motif, ankyrin repeats, and compete with D-type cyclin for binding to CDK4 and 6. The Cip/Kip family comprises p21Cip1, p27Kip1 and p57Kip2. They also share a common structural motif, a CDK-binding-inhibitory domain, at their N-terminals and inhibit a variety of cyclin-CDK complexes. The induction of these CDKIs results in cell cycle exit by inhibiting CDK activities at G1-to-S phase, and induces terminal differentiation of a variety of cell types (Zhang et al. 1998). Since Cip/Kip family proteins are shown to be short-lived proteins with estimated half-lives of 30-60 min (Pagano et al. 1995, Maki \& Howley 1997), the amounts of the proteins in cells appear to be a major determinant for their activities.

Proliferating cell nuclear antigen (PCNA) is a cofactor of DNA polymerase delta and is present in the nucleus (Maga \& Hubscher 2003). It tethers the polymerase to DNA and increases the processivity of the polymerase during DNA replication. Thus it is a marker for cells in early G1 phase and $\mathrm{S}$ phase of the cell cycle. It has been shown that Cip/Kip family proteins contain not only a CDK-bindinginhibitory domain but also a PCNA-binding-inhibitory domain, and that the cell cycle exit by Cip/Kip family proteins requires both $\mathrm{CDK}$ and PCNA inhibitory activities (Waga et al. 1994, Watanabe et al. 1998).

Interestingly, it has been demonstrated that mice lacking p27Kip1 display increased body size with multiple organ hyperplasia including the adrenal medulla (Nakayama et al. 1996). In contrast, p57Kip2-deficient mice showed multiple organ anomalies including adrenocortical hyperplasia (Zhang et al. 1997). A study on the expression of these CDKIs in the developing adrenal glands showed that p27Kip1 and p57Kip2 are mainly expressed in the medulla and cortex respectively (Nagahama et al. 2001). The involvement of $\mathrm{p} 57 \mathrm{Kip} 2$ has been reported in the development of human adrenocortical tumors (Liu et al. 1997, Bourcigaux et al. 2000). These findings indicate that p27Kip1 and p57Kip2 play important roles in the regulation of adrenal cell growth and differentiation. However, little is known about whether ACTH regulates the expression of these CDKIs. In the present study we thus investigated the effects of ACTH on the expression of $\mathrm{p} 27 \mathrm{Kip} 1$, p57Kip2 and PCNA in the adrenal glands of rats treated with dexamethasone (Dex).

\section{Materials and Methods}

\section{Animal treatment}

The experimental protocol was approved by the Committee for Animal Experiment of the Research
Institute of Environmental Medicine, Nagoya University. Male Wistar rats, weighing approximately $180 \mathrm{~g}$, were assigned into three groups: Dex, Dex+ACTH, and control groups (Fig. 1). Dex (Decadron; Banyu, Tokyo, Japan) was administered intraperitoneally at a dose of $4 \mathrm{mg} / \mathrm{kg}$ body weight once a day for 5 days (Dex group). Then, ACTH (Cortrosyn-Z; Daiichi Pharmaceutical Co Ltd, Tokyo, Japan) was injected intramuscularly at a dose of $50 \mathrm{IU} / \mathrm{kg}$ body weight once a day for 3 days (Dex+ACTH group). The rats were killed by decapitation at $12,24,48$ and $72 \mathrm{~h}$ after the initial ACTH administration, and at 4-8 days after ACTH. The rats in the Dex group were also killed by decapitation at 1, 4,6 and 9 days after the last Dex administration. The control rats without Dex and ACTH administration were killed on the eighth day after the initial ACTH administration. The number of rats in each experimental group was five or six. The adrenal glands were excised, cleaned of fat and weighed. For Western blot analysis, glands were frozen immediately in liquid nitrogen and stored at $-80^{\circ} \mathrm{C}$. For immunohistochemistry, the glands were fixed in Zamboni solution overnight and embedded in paraffin.

\section{Antibodies}

Mouse monoclonal antibodies to PCNA and p27Kip1 (BD Transduction Laboratories, San Jose, CA, USA), rabbit polyclonal antibody to p57Kip2 (H-91; Santa Cruz Biotechnology, Santa Cruz, CA, USA) and rabbit polyclonal antibody to actin (Sigma) were used as the first antibodies in Western blot analyses. Goat polyclonal anti-mouse IgG and anti-rabbit IgG antibodies conjugated with horseradish peroxidase (Sigma) were used as the second antibodies. In immunohistochemical analyses, mouse monoclonal antibodies to PCNA or p27Kip1 (BD Transduction Laboratories), and goat polyclonal antibody to p57Kip2 (M-20, Santa Cruz Biotechnology) were used as the first antibodies. Biotinylated anti-mouse $\mathrm{IgG}$ and anti-goat IgG antibodies (Nichirei, Tokyo, Japan) were used as the second antibodies.

\section{Western blot analysis}

The tissue samples were minced and washed with PBS, and dispersed in five volumes of an ice-cold suspension buffer (100 mM NaCl, 10 mM Tris- $\mathrm{HCl}(\mathrm{pH} 7 \cdot 6), 1 \mathrm{mM}$ EDTA $(\mathrm{pH} 8 \cdot 0)$ ) containing protease inhibitor cocktail tablets (Roche). After addition of an equal volume of $2 \times$ SDS gel-loading buffer, the samples were placed in boiling water and sonicated to shear the chromosomal DNA. After centrifugation, the supernatants $(50 \mu \mathrm{g}$ protein per lane) were subjected to $12 \%$ polyacrylamide gel electrophoresis. The protein concentrations were determined by the Bradford method using a kit from BioRad. The detailed procedures for Western blot analysis were described in our previous report (Kikumori et al. 1998). 


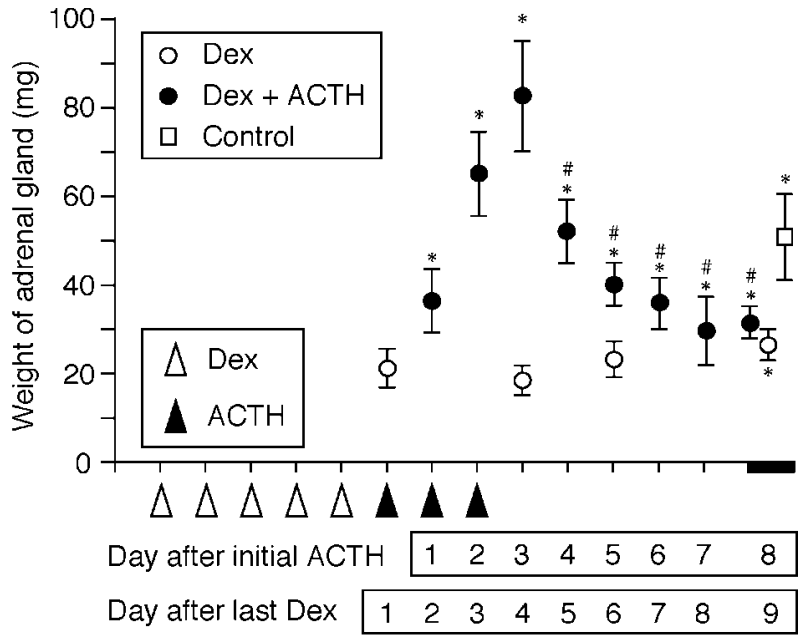

Figure 1 Effects of Dex and ACTH on the weights of adrenal glands. Male Wistar rats, weighing approximately $180 \mathrm{~g}$, were assigned to three groups: Dex, Dex+ACTH and control groups. Dex $(\triangle)$ was administered intraperitoneally once a day for 5 days (Dex group, $\bigcirc$ ). Then, ACTH $(\boldsymbol{\Delta})$ was injected intramuscularly once a day for 3 days (Dex+ACTH group, - ). The rats were killed by decapitation at the indicated times. The control rats without Dex and ACTH administration ( $\square$ ) were killed on the eighth day after the initial ACTH administration. The adrenal glands were excised, cleaned of fat and weighed. Each experimental point consisted of five or six rats. Adrenal weights (mg) are expressed as means \pm S.D. $(n=5$ or 6$)$. ${ }^{*} P<0 \cdot 05$ vs Dex group at 1 day after the last Dex administration; ${ }^{\#} P<0 \cdot 05$ vs Dex $+\mathrm{ACTH}$ group at 3 days after the initial ACTH administration.

The membrane was incubated with the first antibody for $16 \mathrm{~h}$ at $4{ }^{\circ} \mathrm{C}$, followed by incubation with the second antibody for $1 \mathrm{~h}$. The proteins were visualized by enhanced chemiluminescence reagents (Pierce, Rockford, IL, USA), and the images were recorded using the Light Capture chemiluminescence detection system (Atto, Tokyo, Japan). The densities of bands were quantified using NIH image software (version 1.62; National Institutes of Health, Bethesda, MD, USA).

\section{Immunohistochemistry}

Immunohistochemistry was performed mainly using the universal immuno-enzyme polymer (UIP) method (Histofine, simple stain MAX-PO kit; Nichirei). According to the manufacturer's instruction, deparaffinization and rehydration were performed for paraffin-embedded, $3 \mu \mathrm{m}$ thick tissue sections mounted on silane-coated slides. The sections were then exposed to microwave radiation in $1 \mathrm{mM}$ EDTA ( $\mathrm{pH} 8.0$ ) for 9 min to retrieve antigens, and treated with $3 \%$ hydrogen peroxide for $10 \mathrm{~min}$ to quench endogenous peroxidase activity. Non-specific sites were blocked with bovine serum for $10 \mathrm{~min}$. The sections were then incubated overnight at $4{ }^{\circ} \mathrm{C}$ with the first antibody, followed by incubation for $30 \mathrm{~min}$ at room temperature with a Histofine solution that contained amino acid polymers conjugated with peroxidase and the second antibody. After washing, a 3, 3'-diaminobenzidine (DAB) chromogen solution was applied for $5 \mathrm{~min}$. The sections were then counterstained with hematoxylin-eosin and mounted. In some experiments, a labeled streptavidinbiotin (LSAB) method was also carried out using peroxidase-conjugated streptavidin and DAB (LSAB2 Kit; Dako, CA, USA). Double staining was performed by the UIP method, followed by the LSAB method. After the first staining using $\mathrm{DAB}$, the sections were again exposed to microwave radiation for $9 \mathrm{~min}$. They were then incubated with another first antibody at $4{ }^{\circ} \mathrm{C}$ overnight, followed by incubation at room temperature for $10 \mathrm{~min}$ with the biotinylated second antibody and then for $10 \mathrm{~min}$ with alkaline phosphatase-conjugated streptavidin. After washing, a fuchsin solution was applied for $1 \mathrm{~min}$.

\section{Statistical analysis}

Statistical analysis was carried out by one-way fractional ANOVA, followed by Fisher's protected least significant difference (PLSD) analysis. A $P$ value less than 0.05 was considered significant.

\section{Results}

\section{Effects of Dex and ACTH on adrenal gland weight}

As shown in Fig. 1, treatment with Dex for 5 days significantly decreased the weights of adrenal glands at 1 day after the last Dex administration, when compared with those of the control adrenals, suggesting the suppression of endogenous ACTH secretion. Subsequent treatment with ACTH significantly increased the adrenal weights up to $72 \mathrm{~h}$ after the initial ACTH administration. The weights then decreased gradually, suggesting a diminished influence of exogenous ACTH. In contrast, the weights of Dex-treated rats remained unchanged for at least 6 days after the last Dex treatment, suggesting the prolonged suppression of endogenous ACTH secretion in the Dex-treated rats.

\section{ACTH-dependent expression of PCNA}

As shown in Fig. 2A, PCNA was detected as a single band with a molecular mass of $36 \mathrm{kDa}$ by Western blot analysis. Substantial levels of PCNA expression were observed in the control adrenals (Fig. 2B) and treatment with Dex significantly reduced the expression. Subsequent treatment with ACTH increased the expression at $48 \mathrm{~h}$, followed by a further increase at $72 \mathrm{~h}$. No remarkable changes in the actin levels were observed. In agreement with these results, immunohistochemical analysis revealed that a number of PCNA-expressing cells were found in 


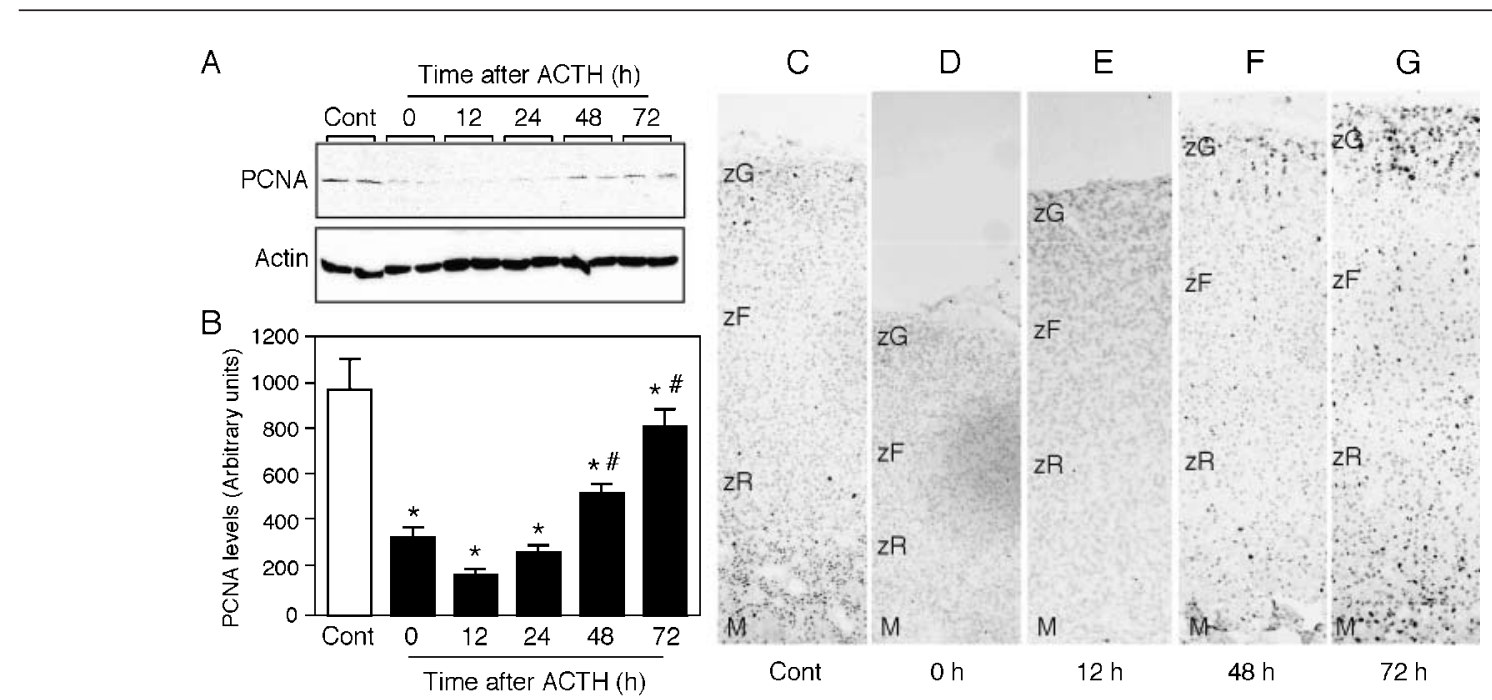

Figure 2 Effects of Dex and ACTH on PCNA expression in rat adrenal. Male Wistar rats were treated with Dex for 5 days to suppress endogenous ACTH secretion $(0 \mathrm{~h})$, and then treated with ACTH for various lengths of time as indicated (12-72 h, see Fig. 1). Whole-tissue lysates prepared from the adrenals were subjected to Western blot analysis using anti-PCNA and anti-actin antibodies. Representative images are shown in (A), 'Cont' indicates the adrenal of non-treated, control rats. The analysis was done in duplicate, and the density of one band represents the expression level in one adrenal. Similar results were obtained from the separate experiments. The expression levels of PCNA were normalized to those of actin, and are expressed in arbitrary units in (B); $n=6 ;{ }^{*} P<0.05$ vs Cont; ${ }^{\#} P<0.05$ vs ACTH 0 h (Dex). Representative results of immunohistochemical analysis using anti-PCNA antibody are shown in (C) to (G). zG, zona glomerulosa; $z F$, zona fasciculata; $z R$, zona reticularis; $M$, medulla.

all zones including the medulla of the control adrenal, with a relatively abundant expression in the zona glomerulosa (Fig. 2C). Dex treatment resulted in a marked shrinkage of the adrenal cortex (Fig. 2D), especially of the zona fasciculata and zona reticularis, and in the disappearance of PCNA-expressing cells in all zones of the adrenal. The PCNA-expressing cells were hardly detected at $12 \mathrm{~h}$ after ACTH (Fig. 2E). At $48 \mathrm{~h}$ after ACTH, the PCNA-expressing cells started to appear in the zona glomerulosa, and at $72 \mathrm{~h}$ they increased markedly (Fig. 2F and G). The PCNA-expressing cells were also observed in other zones of the adrenal, including the medulla at $72 \mathrm{~h}$. These results indicate that most of PCNA-expressing cells detected in the cortex and medulla are under the control of ACTH. Furthermore, it is demonstrated that the cells in the zona glomerulosa are most sensitive and respond rapidly to ACTH.

\section{Rapid decrease in p27Kip1 expression by ACTH}

As shown in Fig. 3A, p27Kip1 was detected as a single band with a molecular mass of $27 \mathrm{kDa}$ by Western blot analysis. Substantial levels of p27Kip1 expression were observed in the control adrenals (Fig. 3B), which were not altered by Dex treatment. Subsequent treatment with ACTH induced rapid and significant suppression of the expression at $12 \mathrm{~h}$, the suppression lasting until $48 \mathrm{~h}$ after ACTH. At $72 \mathrm{~h}$, the levels returned to the control levels.
Since it was reported that p27Kip1 is mainly expressed in the medulla of mice (Nagahama et al. 2001), we determined the localization of p27Kip1-expressing cells in the rat adrenal by immunohistochemical analysis. It was revealed that p27Kip1 was expressed abundantly in the medulla of control adrenal, with a relatively low expression in the zona glomerulosa and the zona fasciculata (Fig. 3C). Dex treatment appeared not to alter this distribution of the p27Kip1-expressing cells in the adrenal, although the expressing cells were condensed because of the shrinkage of the adrenal (Fig. 3D). At 12 and $48 \mathrm{~h}$ after ACTH, the p27Kip1-expressing cells were hardly detected in the cortex, but they were detected in the medulla (Fig. 3E and F), indicating that the decrease in p27Kip1 expression shown by Western blot analysis reflects its reduced expression in the cortex, but not in the medulla. At $72 \mathrm{~h}$, the p27Kip1-expressing cells appeared in the zona glomerulosa (Fig. 3G). In the medulla, p27Kip1-expressing cells were constantly detected.

These results indicate that $\mathrm{p} 27 \mathrm{Kip} 1$ expression in the medulla is not under the control of Dex and ACTH. In contrast, the expression in the cortex is negatively regulated by $\mathrm{ACTH}$ at the earlier time points after ACTH treatment. The prolonged exposure to ACTH, conversely, increases p27Kip1 expression in the zona glomerulosa.

Double immunostaining of PCNA and p27Kip1 in the adrenal at $72 \mathrm{~h}$ after ACTH is shown in Fig. 4. Most of the cells in the zona glomerulosa expressed either PCNA or 
A

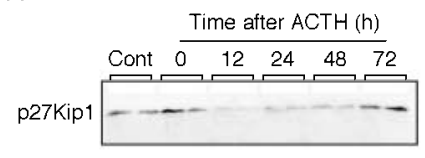

$\mathrm{B}$

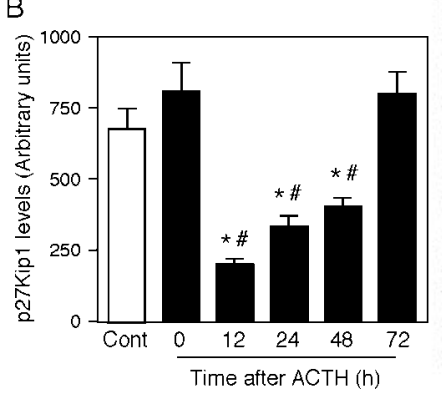

C

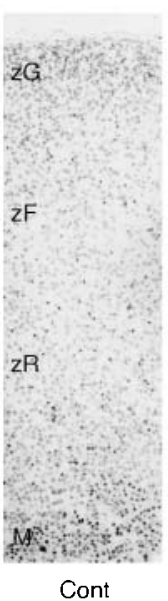

$\mathrm{D}$

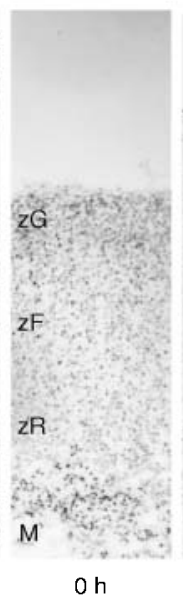

E

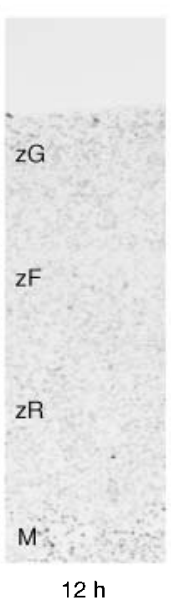

$\mathrm{F}$

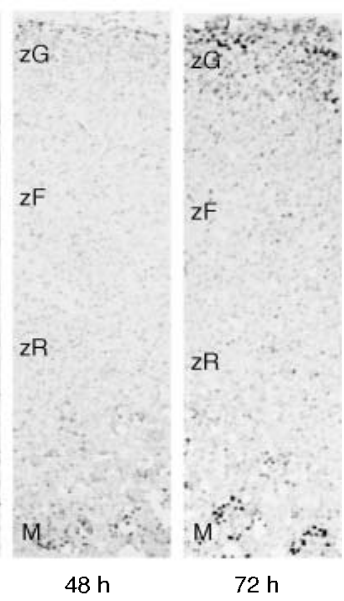

Figure 3 Effects of Dex and ACTH on p27Kip1 expression in rat adrenal. Rats were treated with Dex and ACTH in the same manner as described in Figs 1 and 2. Whole-tissue lysates prepared from the adrenals were subjected to Western blot analysis using anti-p27Kip1 and anti-actin antibodies. A representative image of p27Kip1 is shown in (A); the analysis was performed in duplicate. Similar results were obtained from separate experiments. The expression levels of p27Kip1 were normalized to those of actin, and are expressed in arbitrary units in (B); $n=6$; ${ }^{*} P<0.05$ vs Cont; ${ }^{\#} P<0.05$ vs ACTH 0 h (Dex). Representative results of immunohistochemical analysis using anti-p27Kip1 antibody are shown in (C) to $(G)$.

p27Kip1, indicating the presence of cells at different stages of the cell cycle. It should be noted that some cells appeared to express both proteins, suggesting that p27Kip1 may inhibit cell cycle progression by directly preventing PCNA function. Quantitative analysis revealed that ratios of PCNA-, p27Kip1- and PCNA+ p27Kip1-expressing cells were around 45, 24 and 31\% respectively.

\section{ACTH-dependent induction of p57Kip 2 in the zona glomerulosa}

In contrast to PCNA and p27Kip1, p57Kip2 expression was not detected in the control adrenal as evidenced by Western blot analysis (Fig. 5A) and immunohistochemistry (Fig. 5C), indicating the low expression of p57Kip2, if any, in the rat adrenal. This result was unexpected, since it has been reported that p57Kip2 is mainly expressed in the adrenocortex in mice (Nagahama et al. 2001). p57Kip2 expression was also not detected in the Dex-treated adrenal (Fig. 5A). However, ACTH treatment for $48 \mathrm{~h}$ induced expression in the zona glomerulosa, followed by a marked increase in the same zone (Fig. 5A and D).

\section{Long-term effects of ACTH and Dex on the expression of} PCNA, p27Kip1 and p57Kip2

As shown in Fig. 6A, the long-term effects of ACTH on the expression of PCNA, p27Kip1 and p57Kip2 were examined. PCNA levels rapidly decreased 4 days after the

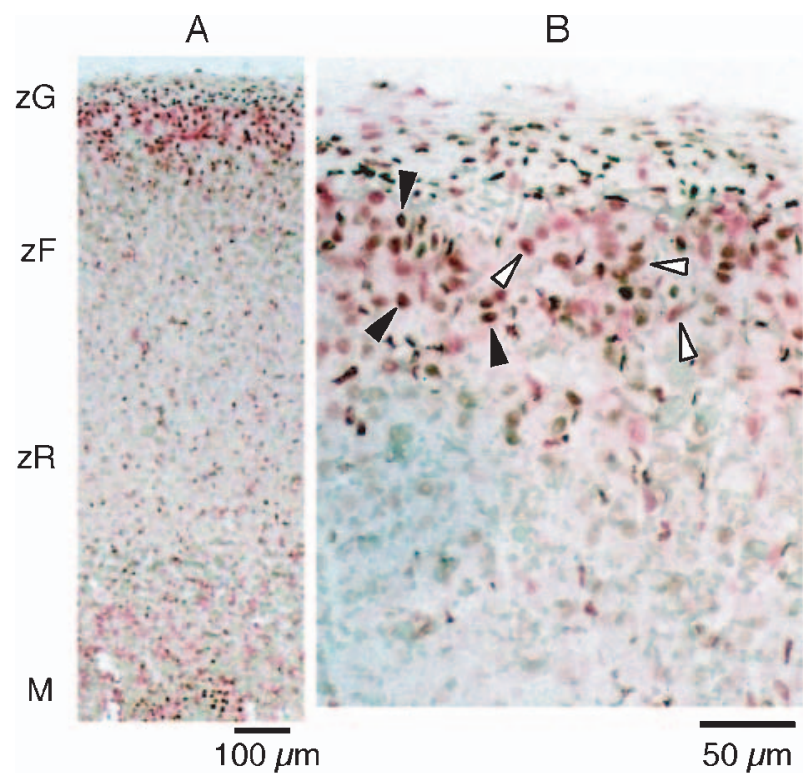

Figure 4 Double staining of PCNA and p27Kip1 in rat adrenal. Sections of adrenals obtained from rats treated with ACTH for $72 \mathrm{~h}$ were double stained with anti-PCNA and anti-p27Kip1 antibodies. The first staining was performed with the UIP method using anti-p27Kip1 antibody and DAB as a chromogen. The subsequent staining was done with the LSAB method using anti-PCNA antibody and fuchsin as a chromogen. The counterstaining was performed with hematoxylin-eosin. The brown and pink staining indicate p27Kip1 and PCNA expression respectively. Closed and open arrowheads indicate the representative $\mathrm{p} 27 \mathrm{Kip} 1$-expressing cells and the p27Kip1+PCNA-expressing cells respectively. 
A

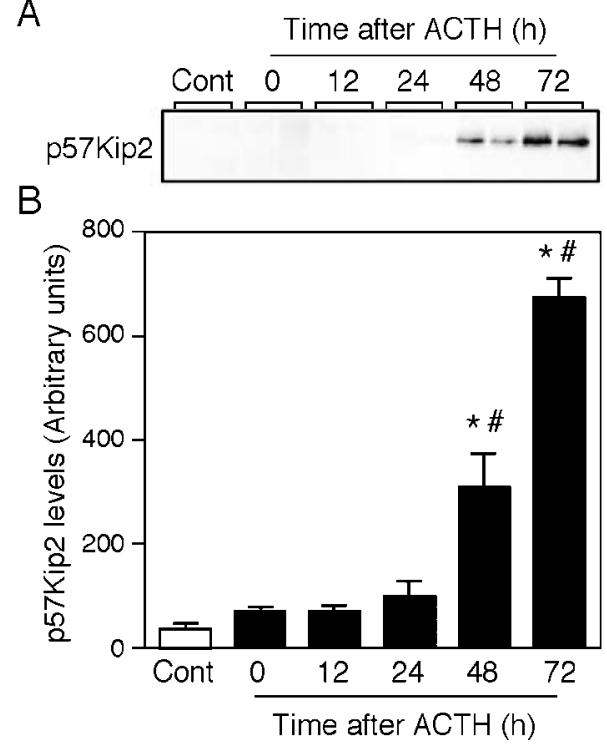

C

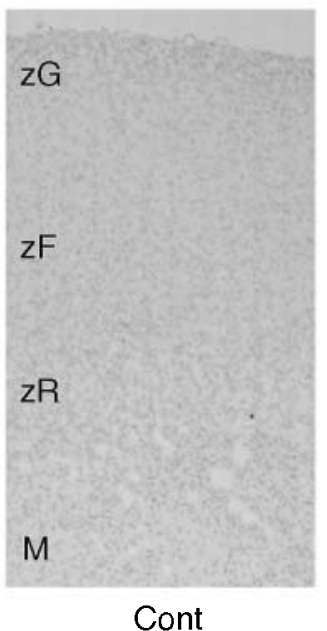

D

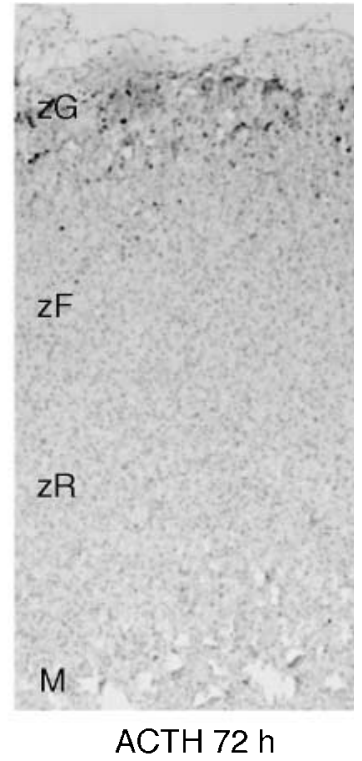

Figure 5 Effects of ACTH on p57Kip2 expression in the rat adrenal. Rats were treated with Dex and ACTH as described in Figs 1 and 2. Whole-tissue lysates prepared from the adrenals were subjected to Western blot analysis using anti-p57Kip2 and anti-actin antibodies. A representative image of p57Kip2 is shown in (A). The analysis was performed in duplicate. Similar results were obtained from separate experiments. The expression levels of p57Kip2 were normalized to those of actin, and are expressed in arbitrary units in (B); $n=6$; ${ }^{*} P<0.05$ vs Cont; ${ }^{\#} P<0.05$ vs $\mathrm{ACTH} 0 \mathrm{~h}$ (Dex). Representative results of immunohistochemical analysis using anti-p57Kip2 antibody are shown in (C) and (D).

initial ACTH administration. Similarly, p57Kip2 levels also decreased 4 days after ACTH and returned to low levels. These changes were concomitant with the decrease in adrenal weights (Fig. 1), indicating that PCNA and p57Kip2 expression is highly dependent on ACTH. In contrast, the high $\mathrm{p} 27 \mathrm{Kip} 1$ levels at 3 days continued up to 4-8 days after ACTH administration, indicating that p27Kip1 expression in this period is not under the control of ACTH.

The long-term effects of Dex were also examined (Fig. 6B). PCNA and p57Kip2 expression were not increased even at 6 days after the last Dex administration. p27Kip1 expression also remained unchanged. These results indicate the prolonged suppression of endogenous ACTH secretion in the Dex-treated rats, which is compatible with the results of adrenal weight measurement (Fig. 1). It is thus concluded that the changes observed in this study in the expression of PCNA, p27Kip1 and p57Kip2 following ACTH administration are not a consequence of either Dex withdrawal or an elevation of endogenous ACTH.

\section{Discussion}

The adrenocortex of mammals consists of three morphologically distinct zones: the zona glomerulosa, the zona fasciculata and the zona reticularis. Generally, mineralocorticoids are synthesized from the cells in the zona glomerulosa under the control of the renin-angiotensin system, whereas the cells in the zona fasciculata produce glucocorticoids under the control of ACTH. The zona reticularis cells produce androgen. However, recent studies have revealed a species variation of these zones at morphological and functional levels. For example, the expression levels of steroidogenic enzymes in the zones have been shown to be considerably different in humans and rats (Vinson 2003). It has also been reported that similar levels of ACTHR are expressed in all three zones of human adrenocortex (Reincke et al. 1998), whereas its expression is mainly in the zona glomerulosa and the zona fasciculata in mice (Xia \& Wikberg 1996, Muller et al. 2001).

The present study was undertaken to investigate the mitogenic action of ACTH on adrenal cells using a rat model. The PCNA-expressing cells first appeared in the zona glomerulosa at $48 \mathrm{~h}$ after ACTH administration, and then such cells were detected not only in the zona fasciculata and zona reticularis but also in the medulla at $72 \mathrm{~h}$. These results indicate that the mitogenic effect of ACTH is initially exerted on the zona glomerulosa where there is a cell population that can initiate proliferation in response to ACTH. Since the abundant ACTHR expression was reported in the zona glomerulosa, it is likely that the mitogenic effect of ACTH is a direct action on the 

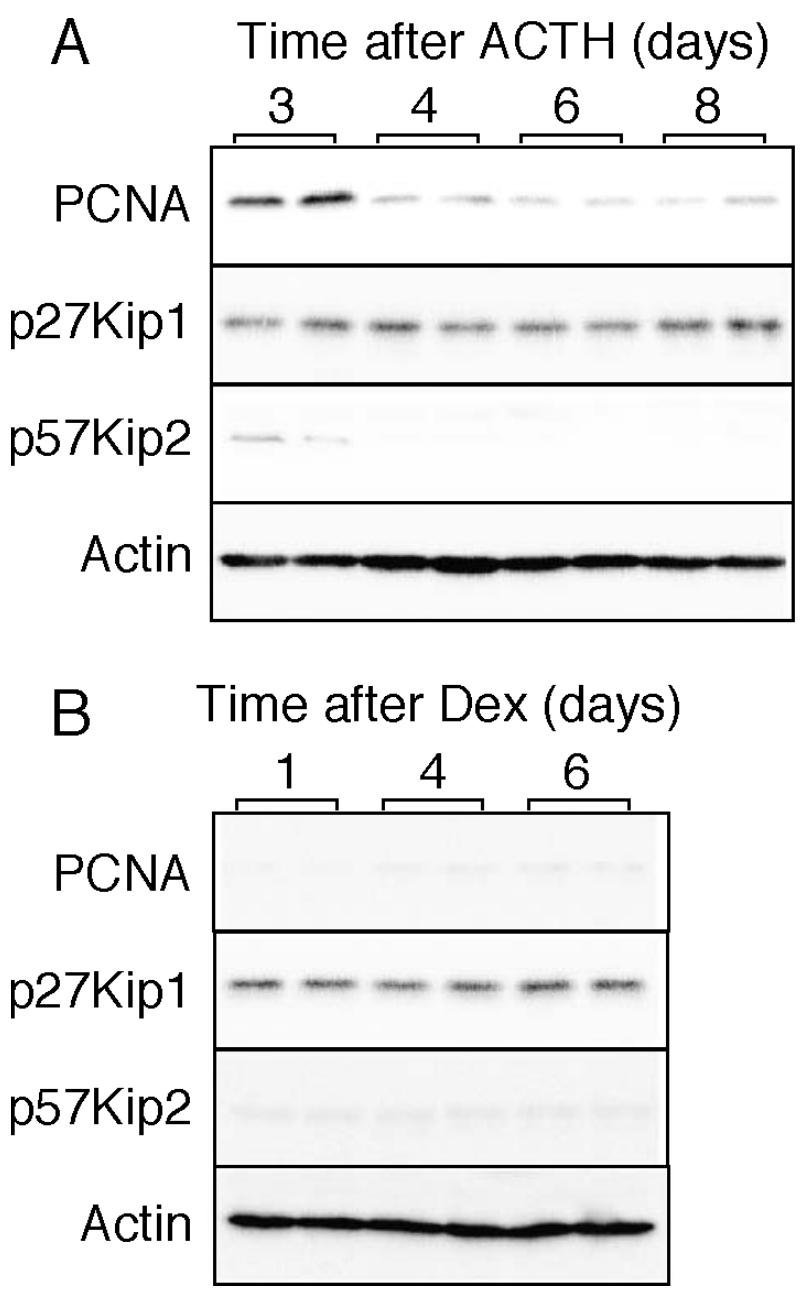

Figure 6 Long-term effects of ACTH and Dex on the expression of PCNA, p27Kip1 and p57Kip2. Whole-tissue lysates prepared from the adrenals of rats treated with Dex+ACTH (A) or only with Dex (B) were subjected to Western blot analysis using anti-PCNA, anti-p27Kip1, anti-p57Kip2 and anti-actin antibodies. The days after the initial ACTH administration (A) or the days after the last Dex administration (B) are indicated at the top of the panel (see Fig. 1). Representative images are shown; the analysis was performed in duplicate and the density of one band represents the expression level in one adrenal. Similar results were obtained from separate experiments.

cells via ACTHR. It has been demonstrated that there exists a zone containing stem cells between the zona glomerulosa and zona fasciculata in adult rats, especially in Sprague-Dawley rats, which is called the zona intermedia or undifferentiated cell zone (Mitani et al. 2003, Vinson 2003), and that cell proliferation in this zone is associated with the circadian rhythm of plasma ACTH levels (Miyamoto et al. 1999). Our results are partially compatible with these reports, although the cell proliferation observed in our study is mainly in the zona glomerulosa, but is not confined to the specific zone. The appearance of the PCNA-expressing cells in the zona fasciculata, the zona reticularis and the medulla at $72 \mathrm{~h}$ after ACTH implies that the site of the ACTH action is not limited to the zona glomerulosa. The appearance may not result from the migration of cells from the zona glomerulosa, because it takes tens of days for the proliferating stem cells to migrate centripetally to the zones (Mitani et al. 1995). These results demonstrate that ACTH promotes cell cycle progression of various types of cells in the adrenal. The broad effects of ACTH were confirmed by the finding that the PCNA-expressing cells were entirely absent in the Dex-treated adrenal.

The medulla was found to be most abundant of the p27Kip1-expressing cells in the normal rat adrenal, compatible with previous reports (Nagahama et al. 2001). In addition, it was found that the expression in the medulla was not affected by Dex or by ACTH, whereas expression in the cortex was markedly affected by ACTH. Of note, the absence of PCNA-expressing cells in the Dex-treated adrenal was concomitant with the presence of p27Kip1expressing cells, but not p57Kip2-expressing cells. Administration of ACTH rapidly and specifically suppressed the p27Kip1 expression in the adrenocortical cells at $12 \mathrm{~h}$ after ACTH administration. These results support the important role of p27Kip1 in ACTH-dependent cell cycle regulation of the adrenocortical cells. In the absence of ACTH, the cells may exit the cell cycle by expressing p27Kip1. When the cells are exposed to $\mathrm{ACTH}$, the suppression of p27Kip1 may trigger cell cycle progression.

On the other hand, prolonged exposure to ACTH induced p27Kip1 expression in the zona glomerulosa at $72 \mathrm{~h}$, indicating that ACTH stimulates not only proliferation but also cell cycle arrest of adrenocortical cells (Dallman et al. 1980). Co-expression of p27Kip1 and PCNA in some cells in the zona glomerulosa suggests a direct inhibitory action of p27Kip1 on PCNA, as shown in previous reports (Waga et al. 1994, Watanabe et al. 1998). Similar bidirectional effects of ACTH were observed in mouse Y1 adrenocortical tumor cells (Lotfi et al. 1997, Forti et al. 2002). It was reported that a brief pulse exposure to ACTH stimulates the growth of Y1 cells in a cAMP-independent manner, but that continuous exposure inhibits the growth in a cAMP-dependent manner. The growth inhibition is accompanied by the induction of p27Kip1.

In contrast to the expression of p27Kip1, p57Kip2 expression has been reported to be restricted in the adrenocortex of mice and humans (Nakayama et al. 2001, Thomas et al. 2001). However, our study showed that p57Kip2 expression was minimal in all zones of the control and Dex-treated rat adrenals. Administration of ACTH markedly induced the expression in the zona glomerulosa at $48 \mathrm{~h}$, when p27Kip1 was still suppressed. At $72 \mathrm{~h}$, a further increase of p57Kip 2 in the zona glomerulosa was observed. No p57Kip2 expression was 
detected in the medulla. These results indicate that p57Kip2 and p27Kip1 expression in rat adrenal is differentially regulated by $\mathrm{ACTH}$, suggesting distinct roles for the two CDKIs in cell cycle regulation of adrenal cells. p57Kip2 may compensate the p27Kip1 function in the zona glomerulosa in response to ACTH, especially to its prolonged exposure.

In conclusion, this is the first demonstration that ACTH regulates the expression of p27Kip1 and p57Kip2 in the rat adrenal in a time- and site-dependent manner. It should be noted that the ACTH-dependent expression of PCNA and CDKIs is most vividly observed in the zona glomerulosa. It is thus suggested that ACTH modulates proliferation and probably differentiation of adrenocortical cells in the zona glomerulosa by regulating p27Kip1 and p57Kip2 expression.

\section{Funding}

This work was supported in part by Grant-in-Aid for Scientific Research from the Ministry of Education, Science, Sports, and Culture, Japan. The authors declare that there is no conflict of interest that would prejudice the impartiality of this scientific work.

\section{References}

Arola J, Heikkila P, Voutilainen R \& Kahri AI 1993 Role of adenylate cyclase-cyclic AMP-dependent signal transduction in the ACTH-induced biphasic growth effect of rat adrenocortical cells in primary culture. Journal of Endocrinology 139 451-461.

Bland ML, Desclozeaux M \& Ingraham HA 2003 Tissue growth and remodeling of the embryonic and adult adrenal gland. Annals of the New York Academy of Sciences 995 59-72.

Bourcigaux N, Gaston V, Logie A, Bertagna X, Le Bouc Y \& Gicquel C 2000 High expression of cyclin E and G1 CDK and loss of function of p57KIP2 are involved in proliferation of malignant sporadic adrenocortical tumors. Journal of Clinical Endocrinology and Metabolism 85 322-330.

Dallman MF, Engeland WC, Holzwarth MA \& Scholz PM 1980 Adrenocorticotropin inhibits compensatory adrenal growth after unilateral adrenalectomy. Endocrinology 107 1397-1404.

Forti FL, Schwindt TT, Moraes MS, Eichler CB \& Armelin HA 2002 ACTH promotion of $\mathrm{p} 27(\mathrm{Kip} 1)$ induction in mouse $\mathrm{Y} 1$ adrenocortical tumor cells is dependent on both PKA activation and Akt/PKB inactivation. Biochemistry 41 10133-10140.

Hornsby PJ \& Gill GN 1977 Hormonal control of adrenocortical cell proliferation. Desensitization to ACTH and interaction between ACTH and fibroblast growth factor in bovine adrenocortical cell cultures. Journal of Clinical Investigation 60 342-352.

Imai T, Seo H, Murata Y, Ohno M, Satoh Y, Funahashi H, Takagi H \& Matsui N 1990 Adrenocorticotropin increases expression of c-fos and beta-actin genes in the rat adrenals. Endocrinology 127 1742-1747.

Kater CE, Biglieri EG, Brust N, Chang B, Hirai J \& Irony I 1989 Stimulation and suppression of the mineralocorticoid hormones in normal subjects and adrenocortical disorders. Endocrine Review 10 149-164.

Kikumori T, Kambe F, Nagaya T, Imai T, Funahashi H \& Seo H 1998 Activation of transcriptionally active nuclear factor-kappaB by tumor necrosis factor-alpha and its inhibition by antioxidants in rat thyroid FRTL-5 cells. Endocrinology 139 1715-1722.

Liu J, Kahri AI, Heikkila P \& Voutilainen R 1997 Ribonucleic acid expression of the clustered imprinted genes, p57KIP2, insulin-like growth factor II, and H19, in adrenal tumors and cultured adrenal cells. Journal of Clinical Endocrinology and Metabolism 82 1766-1771.

Lotfi CF, Todorovic Z, Armelin HA \& Schimmer BP 1997 Unmasking a growth-promoting effect of the adrenocorticotropic hormone in Y1 mouse adrenocortical tumor cells. Journal of Biological Chemistry 272 29886-29891.

Maga G \& Hubscher U 2003 Proliferating cell nuclear antigen (PCNA): a dancer with many partners. Journal of Cell Science 116 3051-3060.

Maki CG \& Howley PM 1997 Ubiquitination of p53 and p21 is differentially affected by ionizing and UV radiation. Molecular and Cellular Biology 17 355-363.

Mitani F, Ogishima T, Miyamoto H \& Ishimura Y 1995 Localization of P450 aldo and P45011 beta in normal and regenerating rat adrenal cortex. Endocrine Research 21 413-423.

Mitani F, Mukai K, Miyamoto H, Suematsu M \& Ishimura Y 2003 The undifferentiated cell zone is a stem cell zone in adult rat adrenal cortex. Biochimica et Biophysica Acta 1619 317-324.

Miyamoto H, Mitani F, Mukai K, Suematsu M \& Ishimura Y 1999 Studies on cytogenesis in adult rat adrenal cortex: circadian and zonal variations and their modulation by adrenocorticotropic hormone. Journal of Biochemistry (Tokyo) 126 1175-1183.

Muller MB, Preil J, Renner U, Zimmermann S, Kresse AE, Stalla GK, Keck ME, Holsboer F \& Wurst W 2001 Expression of CRHR1 and CRHR 2 in mouse pituitary and adrenal gland: implications for HPA system regulation. Endocrinology 142 4150-4153.

Nagahama H, Hatakeyama S, Nakayama K, Nagata M \& Tomita K 2001 Spatial and temporal expression patterns of the cyclin-dependent kinase (CDK) inhibitors p27Kip1 and p57 Kip2 during mouse development. Anatomy and Embryology (Berlin) 203 77-87.

Nakayama K, Ishida N, Shirane M, Inomata A, Inoue T, Shishido N, Horii I \& Loh DY 1996 Mice lacking p27(Kip1) display increased body size, multiple organ hyperplasia, retinal dysplasia, and pituitary tumors. Cell 85 707-720.

Pagano M, Tam SW, Theodoras AM, Beer-Romero P, Del Sal G, Chau V, Yew PR, Draetta GF \& Rolfe M 1995 Role of the ubiquitin-proteasome pathway in regulating abundance of the cyclin-dependent kinase inhibitor p27. Science 269 682-685.

Reincke M, Beuschlein F, Menig G, Hofmockel G, Arlt W, Lehmann R, Karl M \& Allolio B 1998 Localization and expression of adrenocorticotropic hormone receptor mRNA in normal and neoplastic human adrenal cortex. Journal of Endocrinology 156 415-423.

Rosenfeld RS, Rosenberg BJ, Fukushima DK \& Hellman L 1975 24-Hour secretory pattern of dehydroisoandrosterone and dehydroisoandrosterone sulfate. Journal of Clinical Endocrinology and Metabolism 40 850-855.

Sherr CJ \& Roberts JM 1999 CDK inhibitors: positive and negative regulators of G1-phase progression. Genes and Development 13 1501-1512.

Thomas M, Popnikolov NK, Scott C, Smith JR \& Hornsby PJ 2001 Contrasting roles of $\mathrm{p} 57$ (KIP2) and $\mathrm{p} 21$ (WAF1/CIP1/SDI1) in transplanted human and bovine adrenocortical cells. Experimental Cell Research 266 106-113.

Vidal A \& Koff A 2000 Cell-cycle inhibitors: three families united by a common cause. Gene 247 1-15.

Vinson GP 2003 Adrenocortical zonation and ACTH. Microscopy Research and Technique 61 227-239.

Waga S, Hannon GJ, Beach D \& Stillman B 1994 The p21 inhibitor of cyclin-dependent kinases controls DNA replication by interaction with PCNA. Nature 369 574-578. 
Watanabe H, Pan ZQ, Schreiber-Agus N, DePinho RA, Hurwitz J \& Xiong Y 1998 Suppression of cell transformation by the cyclin-dependent kinase inhibitor p57KIP2 requires binding to proliferating cell nuclear antigen. PNAS 95 1392-1397.

Wright NA, Appleton DR \& Morley AR 1974 Effect of dexamethasone on cell population kinetics in the adrenal cortex of the prepubertal male rat. Journal of Endocrinology 62 527-536.

Xia Y \& Wikberg JE 1996 Localization of ACTH receptor mRNA by in situ hybridization in mouse adrenal gland. Cell and Tissue Research 286 63-68.

Zhang P, Liegeois NJ, Wong C, Finegold M, Hou H, Thompson JC, Silverman A, Harper JW, DePinho RA \& Elledge SJ 1997 Altered cell differentiation and proliferation in mice lacking p57KIP2 indicates a role in Beckwith-Wiedemann syndrome. Nature 387 151-158.

Zhang P, Wong C, DePinho RA, Harper JW \& Elledge SJ 1998 Cooperation between the Cdk inhibitors p27(KIP1) and p57(KIP2) in the control of tissue growth and development. Genes and Development 12 3162-3167.

Received in final form 14 February 2005

Accepted 15 February 2006

Made available online as an Accepted Preprint 17 February 2006 